\title{
The preference of the physicians in diagnosis and treatment of cardiovascular diseases
}

\author{
Lütfü Bekar ${ }^{\mathrm{a}}$, Mehdi Zoghi ${ }^{\mathrm{b}, *}$, on behalf of the CAS-TR group ${ }^{1}$ \\ a Hitit University, Department of Cardiology, Çorum, Turkey \\ ${ }^{\mathrm{b}}$ Ege University, Department of Cardiology, Izmir, Turkey
}

\section{A R T I C L E I N F O}

\section{Article history:}

Received 21 February 2017

Received in revised form 18 May 2017

Accepted 21 May 2017

Available online 18 July 2017

\section{Keywords:}

Questionnaire

Cardiovascular disease

Hypertension

Treatment

\begin{abstract}
A B S T R A C T
Objective: To evaluate opinions and applications of physicians related to cardiovascular diseases in their daily practice about current diagnosis, treatment and prophylaxis of coronary artery disease, acute coronary syndrome and hypertension.

Method: In this study, a questionnaire survey was performed with cardiologists, internists, family physicians and neurologists about the current diagnosis, treatment and prophylaxis in cardiovascular diseases.

Results: A total of 208 physicians participate in the study. Most of the physicians were working in the specialty of cardiology (88.94\%). Majority of physicians (47.6\%) had a professional experience of more than ten years and $56.25 \%$ of them were working in the training and research hospitals or state hospitals.

Conclusion: The clinical applications of physicians are mostly in compliance with the treatment guidelines.

(C) 2016 The Society of Cardiovascular Academy. Production and hosting by Elsevier B.V. This is an open access article under the CC BY-NC-ND license (http://creativecommons.org/licenses/by-nc-nd/4.0/).
\end{abstract}

\section{Introduction}

In recent years, new evidence has been obtained related to the diagnosis and treatment of cardiovascular diseases. As a result, many pharmacologic and nonpharmacologic treatment methods have been introduced into clinical practice. ${ }^{1-6}$ Comprehensive improvements in diagnosis and treatment have taken place. In this questionnaire survey, evaluation of the opinions and applications of the physicians related to cardiovascular diseases in their daily practice about current methods of diagnosis, treatment and prophylaxis of cardiovascular diseases was aimed.

\footnotetext{
* Corresponding author.

E-mail address: mehdi_zoghi@hotmail.com (M. Zoghi).

1 Yalım Z, Isgandarov K, Yüksek U, Uygun T, Çelebi ÖÖ, Esin M, Emren SV, Canpolat U, Dolay C, Akçay M, Taşcanov MB, Bayar N, Çelik O, Göktuğ A, Karaarslan O, Kilit C, Günaydın ZY, Ekmekçi C, Yurtdaș M, Yüce Eİ, Akyüz AR, Çelebi AS, Asarcıklı LD, Kalyoncuoğlu M, Dönmez C, Işı IB, Kemal HS, Boyraz B, Unğan I, Sımsır IY, Kocabas U, Günes H, Özgür V, Gülcan M, Hosscan Y, Örnek E, Aksakal A, Alkan MB, Kadı H, Günay S, Bozdemir H, Güven A, Turgut O, Kış M, Şimşek EC, Çatırlı S, Eren H, Doğan A, Uzun HG, Buğan B, Çetin N, Keçegil HT, Güvenç TS, Çekici Y, Demirkıran S, Çelik A, Akıl MA, İlkay A, Harbalıoğlu H, Kanbakan A, Ballı M, Yetim M, Yayla C, Keleș F, Demir FA, Tunç E, Aytemiz F, Çamkıran V, Umdu E, Özde C, Akıncı S, Doğan T, Tosun V, Sökmen Y, Kılıç S, Gül S, Kırdar C, Karademirci M, Seçen Ö, Kalçık M, Baysal S, Gümrükçüoğlu HA, Yenerçağ M, Alıcı H, Duz R, Tarı ÇK, Usalp S, Akyüz A, Çelik A, Kurmuş Ö, Tülüce K, Hoşoğlu Y, Demirelli S, Yılmaz GM, Adalı MK, Okyay K, Çiçek M, Doğan YH, Akyel S, Süner A, Tülüce SY, Yayla C, Ulupınar H, Karaaslan ÖÇ, Ertaş F, Şalk N, Çabuk G, Sığırcı S, Serin SO, Çakır H, Şahan AG, Kudat H, Demir V, Samsa M, Oktay V, Vuran Ö, Yerkesikli B, Şenerdem ME, Ekinözü İ.

Peer review under responsibility of The Society of Cardiovascular Academy.
}

\section{Methods}

In this study, a questionnaire survey consisting of a total of 21 questions was performed with cardiologists, internists, family physicians, emergency medicine specialist and neurologists about current diagnosis, treatment and prophylaxis in cardiovascular diseases (Table 1). The physicians were invited to participate in the survey only via emails and questions were responded via e-mail. At the end of the questionnaire survey, the physicians were asked if their responses could be used for scientific processes and the responses of the assented physicians were analyzed. Approval of the local ethics committee for the study was obtained (2016/047).

\section{Results}

The questionnaire was completed by 214 physicians and 208 physicians allowed the data retrieved from the questionnaire to be analyzed within the frame of the study. The physicians participating in the study consisted of those working in the specialties of cardiology $(n=185$; $88.9 \%)$, internal medicine ( $n=9 ; 4.33 \%)$, emergency services $(n=7$; $3.37 \%)$, family medicine $(n=62 ; 88 \%)$ and neurology $(n=1 ; 0.48 \%)$. The majority of the physicians $(47.60 \%)$ had a professional life longer than ten years. The $56.25 \%$ of the physicians were working in training and research hospitals or state hospitals, $28.37 \%$ in universities, $12.5 \%$ in private hospitals and $2.88 \%$ in medical centers. (Table 2 ). The $66 \%$ prescribed ACE-inhibitors as their first choice in stage 1 hypertensive patients. More than half of the physicians had not used cardiovascular risk scoring system. The $73.5 \%$ of the attendees stated that outcomes 
Table 1

Questions (Q) of the questionnaire survey are seen.

Q1: Please select your area of specialization

Q2: How many years have you been working as a physician?

Q3: Please indicate your academic status.

Q4: In which institution do you work?

Q5: Which the cardiovascular risk scoring systems do you use in your daily practice?

Q6: Do you require an 8-hour fasting condition while evaluating your patient's lipid panel?

Q7: Which patient population is your target in your daily practice of PCSK9 inhibitors?

Q8: Which of the following do you prefer as a primary treatment in a patient with AF who didn't undergo stenting after STEMI and has a CHA2DS2VASc score of 3?

Q9: Which of the following would you prefer as the first drug option in the pharmacological cardioversion for a patient with sudden AF, if the patient has hypertension, LVH and is hemodynamically stable?

Q10: When do you prefer Ticagrelor treatment instead of aspirin for the long-term treatment for secondary prevention?

Q11: In which order do you prefer the following combinations in the treatment of hypertension? (put them in order from 1 to 5 )

Q12: At which rate do you need fixed-dose triple combination therapy in the hypertension treatment?

Q13: At which rate do you prefer Clopidogrel after ACS?

Q14: Do you think that too much statin is used in our country?

Q15: Which drug group do you prefer most in the treatment of stage 1 hypertension?

Q16: Who should evaluate CT angiography?

Q17: Which of the following patient profile(s) is/are not at high risk according to you?

Q18: What is your preference of the treatment for a case with STEMI diagnosis?

Q19: Did the results of the SPRINT study alter your target blood pressure value in high-risk group patients?

Q20: A 42-year-old asymptomatic patient who had an anterior MI one month ago and underwent primary $\mathrm{PCl}$ was referred to your polyclinic for routine control. You see that the medical treatment continues as suggested by guidelines, but the LVEF value is between $25-30 \%$. What would be your ICD preference for this case? Q21: For which patients do you prefer a bioresorbable stent?

Q22: Do you allow the answers given in the current survey to be used for scientific purposes?

of SPRINT study would not change target blood pressure value. Fixeddose triple-combination was required $>20 \%$ in clinical practice of $18.27 \%$ of the attendees. The $29 \%$ believed that statins are prescribed much more than needed. Most of the physicians participating in the study would prefer PCSK9 inhibitors mostly in cases with familial hypercholesterolemia. The $67 \%$ of participants performed $\mathrm{PCI}$ for seven days a week and $24 \mathrm{~h}$ a day or they transferred these patients to a center where PCI could be performed. However, the half of them still preferred clopidogrel following acute coronary syndrome (ACS). Moreover, 53\% of participants did not use any cardiovascular risk-scoring tool.

\section{Table 2}

The table shows the institutions in which physicians participated in the survey are working.

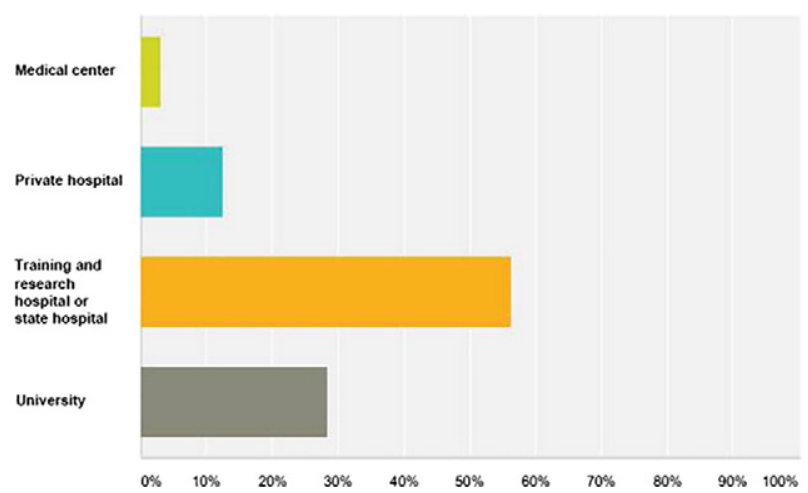

Table 3

The cardiovascular risk scoring systems preferred by the physicians in daily practice are seen.

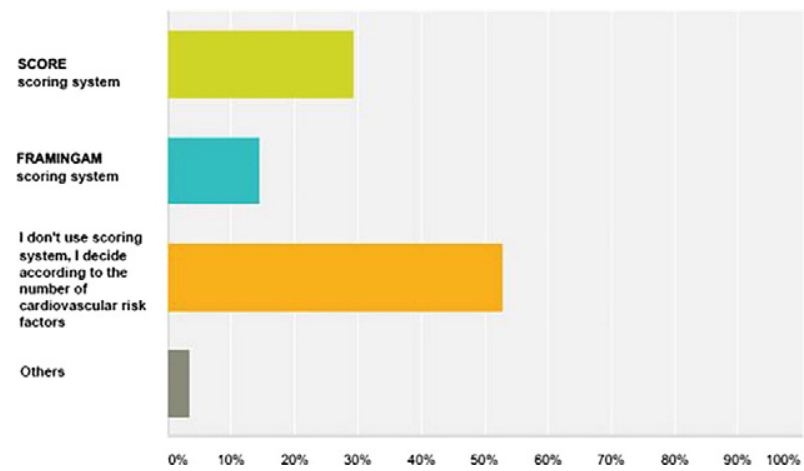

\section{Discussion}

Cardiovascular diseases are among important causes of morbidity and mortality worldwide. Their prevalence gradually increases because of prolongation of expected life span, variations in life style and technologic developments in the field of medicine. ${ }^{7-9}$ In recent years, despite raised awareness of cardiovascular diseases and steps taken during the fight against risk factors, these diseases are important causes of mortality both in developed and developing countries. ${ }^{10,11}$

Cardiovascular disease is still the main cause of cardiac death worldwide. Therefore, the identification of risky population and assessing the risk of cardiovascular disease is essential. ${ }^{12,13}$ Numerous risk-scoring models like WHO model, SCORE, JBS-2, QRISK, and ASSIGN are available. ${ }^{14,15}$ In our study, we have detected that more than half of the physicians had not used cardiovascular risk scoring system however the majority of users had a preferred SCORE risk scoring system (Table 3).

Atherosclerosis is the most frequent cause of cardiovascular diseases. Lipids play a role in the development of atherosclerosis. Treatment of hyperlipidemia is associated with decreased cardiovascular mortality. ${ }^{16}$ Decreasing LDL-cholesterol levels gains priority in the cardiovascular prophylaxis. ${ }^{17}$ In clinical application, lipid panel is evaluated after 8-12 h of fasting. However, most of the individuals eat three main meals and snacks every day and feel fullness all day long. This condition has created concerns in that fasting lipid panel would not reflect cardiovascular risk. However, when fasting and postprandial lipid panels were compared, the difference was detected to be clinically insignificant. ${ }^{18}$ Hyperlipidemia Guideline of European Society of Cardiology indicated that lipid panel could be performed during both fasting and state of satiety. However, the guideline-recommended follow-up of the patients during fasting state in case of hypertriglyceridemia. ${ }^{19}$ In the study, during evaluation of lipid panel by physicians, most of the physicians indicated that they stipulated for fasting condition. A small percentage

\section{Table 4}

Table shows the answers regarding whether physicians were looking for $8 \mathrm{~h}$ of fasting before investigating lipid profile.

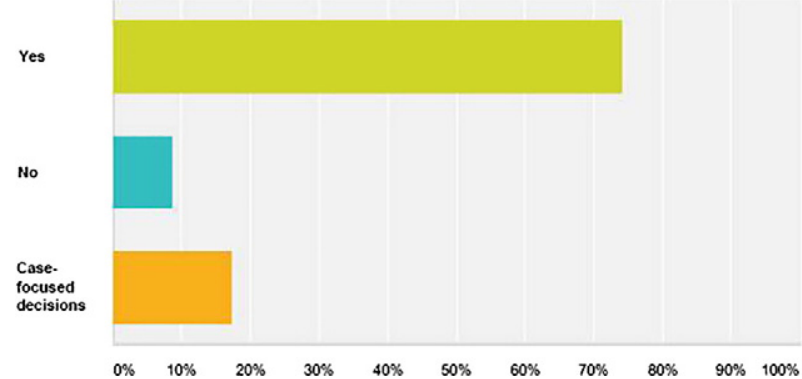


Table 5

The table shows the answers of the physicians participated in the survey regarding whether statins were overused in our country.

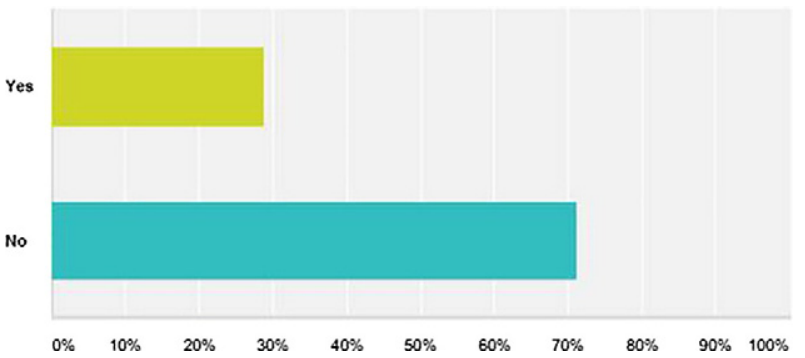

(17.3\%) of the participants reported that they made case-focused decisions (Table 4).

Currently, statins are the most frequently used agents in the treatment of hyperlipidemia. They are recommended for primary and secondary prophylaxis against cardiovascular diseases. ${ }^{20,21}$ However, under statin treatment target LDL-C level is achieved at a low level. Nearly $10-20 \%$ of the patients cannot use statin because of the development of statin tolerance. Whereas, ezetimibe and niacin decrease LDL-C only slightly and their effect on cardiovascular prophylaxis is debatable. ${ }^{22}$ Statins are the very much-debated drugs among cardiovascular drugs in the media. Debates about the uselessness of these drugs or their many side effects are continuing. However, the great majority of our attendees believe that statins are not over-prescribed in Turkey (Table 5).

PCSK9 inhibitors in the treatment of hyperlipidemia are a novel and promising alternative. With these drugs, much more decrease in LDL-C levels has been achieved and cardiovascular events have also demonstrated a tendency to decrease. ${ }^{23}$ In the light of available evidence PCSK9 inhibitors have found an indication of use in patients with high risk who cannot attain target LDL-C levels under statin therapy and in patients with familial hyperlipidemia. ${ }^{19}$ Most of the physicians participating in the study stated that they would prefer this drug and use mostly in cases with familial hypercholesterolemia while $19 \%$ of them expressed that they wouldn't feel a need to use this new group agent at all (Table 6).

Hypertension is an important public health problem prevalent in the community and causes life-threatening complications. The objective of antihypertensive treatment is to decrease blood pressure, cardiovascular mortality and morbidity. ${ }^{24}$ Decreasing blood pressure is known to decrease unwanted events. However, the extent of this drop has been a matter of debate.

In ACCORD study performed on diabetic patients with increased cardiovascular risk, the incidence of unwanted events did not differ between patients who were under strict blood pressure $(<120 \mathrm{~mm} \mathrm{Hg})$ control and patients in whom normal blood pressure levels $(<140 \mathrm{~mm} \mathrm{Hg})$

\section{Table 6}

The answers of the physicians regarding the place of PCSK9 inhibitors in daily practice are seen.

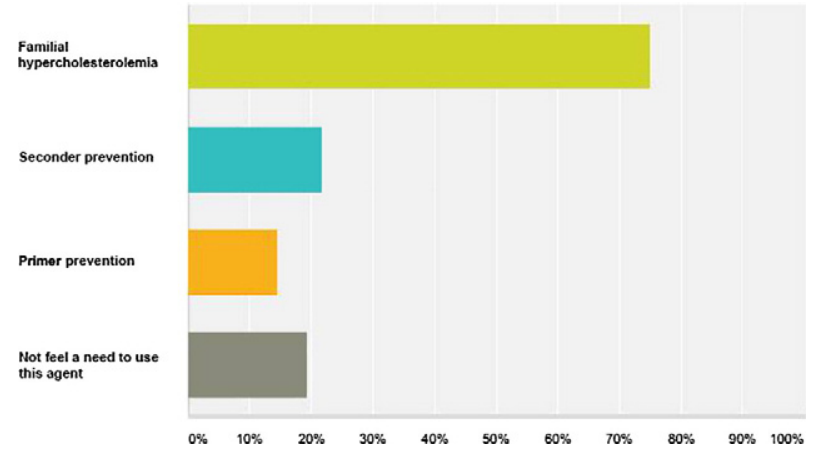

Table 7

The table shows the answers concerning whether the results of the "SPRINT" study have changed the target blood pressure levels in high-risk patients.

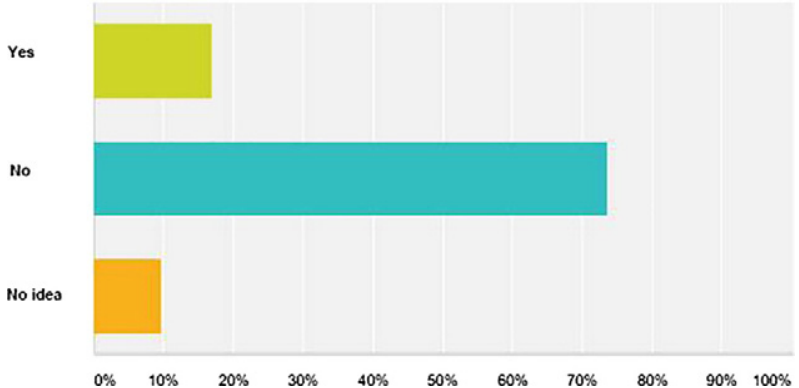

were achieved. ${ }^{25}$ Still as demonstrated in SPRINT study where nondiabetic patients with an increased cardiovascular risk were enrolled, selection of target blood pressure as $120 \mathrm{~mm} \mathrm{Hg}$ rather than $140 \mathrm{~mm} \mathrm{Hg}$, decreased fatally and nonfatal cardiovascular events. ${ }^{26}$ Possibly, with SPRINT study, the necessity to determine target blood pressures again in patients with increased cardiovascular risk will arise. However, in our questionnaire survey, most of the physicians (73.5\%) stated that outcomes of SPRINT study would not change target blood pressure value (Table 7).

Blood pressure control in the treatment of hypertension is mostly achieved by combination treatment rather than monotherapy. In a meta-analysis, it has been determined that combination of two different drugs at lower concentrations induced a more dramatic decrease in blood pressure when compared with the maximum dose of a single drug. ${ }^{27}$ When we asked the physicians about their selection of antihypertensive combination, most frequently angiotensin-converting enzyme inhibitor (ACE-I) plus diuretic combination was preferred, followed by (in order of decreasing frequency) ACE-I + calcium canal blocker, angiotensin II receptor blocker (ARB) + diuretic, and ARB + calcium canal blocker and $\beta$-blocker + diuretic (Table 8). Fixed triple dose combination was preferred by $<10 \%$ of the physicians.

As is known, beta-blocker, diuretic, calcium canal blockers and renin-angiotensin system inhibitors decrease blood pressure and unwanted cardiovascular events. Nowadays, most frequently RAS blockers are used for the treatment of hypertension. The two most frequently preferred members of this group are ACE-I, and ARBs. ${ }^{28}$ In our questionnaire, survey physicians reported their first preference for the treatment of stage I hypertension as ACE-I (Table 9).

Left ventricular hypertrophy (LVH) is one of the important target organ injuries caused by hypertension. LVH is a strong independent risk factor for arrhythmias as atrial fibrillation (AF) ${ }^{29}$ Achievement of sinus rhythm leads to symptomatic improvement and increase in quality of life. The selection of the drug to be used for pharmacologic cardioversion is based on underlying pathology. In hypertensive heart disease, the first drug to be selected is dronedarone followed by amiodarone. ${ }^{30}$ In our questionnaire survey, the first preference was amiodarone for

Table 8

The preferences of the physicians on antihypertensive drugs are seen.

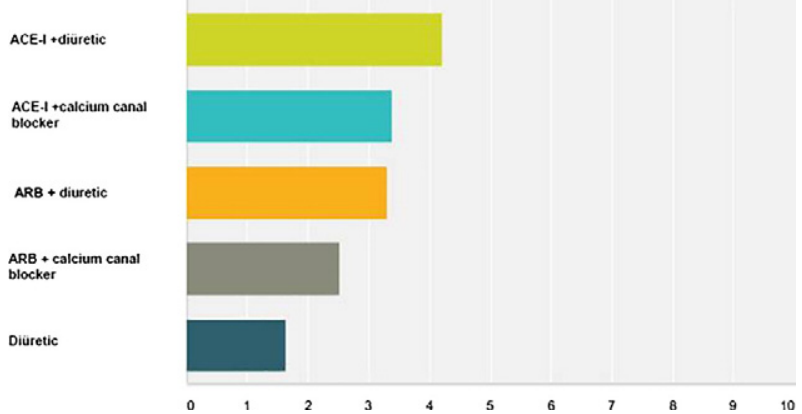


Table 9

The preferences of the physicians on drugs in Stage 1 hypertension.

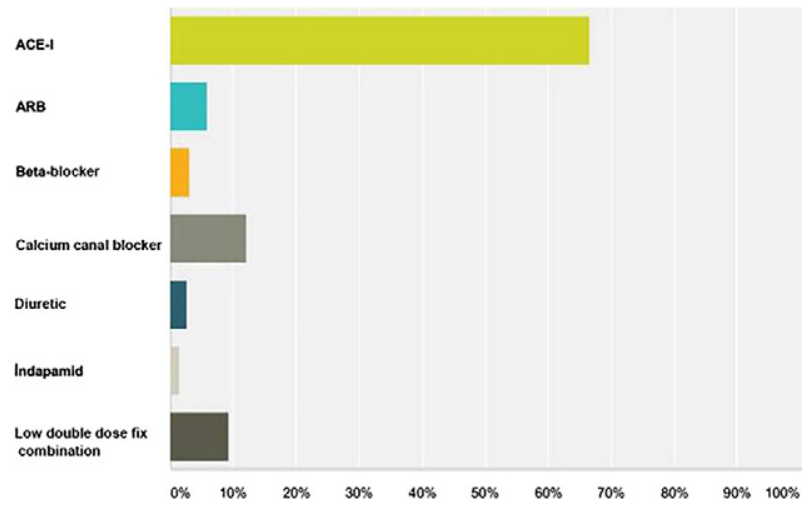

pharmacologic cardioversion in hypertensive LVH patients with the stable hemodynamic state who experienced sudden AF attacks, which was consistent with guideline recommendation (Table 10).

The main component of the treatment for ST-elevation myocardial infarction (STEMI) is the achievement of coronary reperfusion. Coronary reperfusion can be achieved with thrombolytic treatment or percutaneous coronary intervention ( $\mathrm{PCI}$ ). If it can be performed by an experienced team within the first 120 min after the first medical contact, $\mathrm{PCI}$ is more advantageous than thrombolytic treatment. ${ }^{31}$ Most of the study participants stated that they could perform PCI for seven days a week and $24 \mathrm{~h}$ a day or they transferred these patients to a center where PCI could be performed. Only a relatively low percentage of physicians used thrombolytic treatment.

As the part of new developments in stent technology, absorbable stents have been introduced into clinical use. Nearly one-third of the physicians reported that they would prefer to use the stent for diabetic patients with middle-long lesions of LAD, while other one-third of them indicated that they would never advise them.

The Cardiac computed tomography angiography (CCTA) is most commonly performed by radiologist however; the $81 \%$ of attendees were against the evaluation of CCTA by only radiologists.

Following an episode of ACS long-term use of dual anti-aggregant is required. In addition, the use of ticagrelor as an adjunct to aspirin is known to decrease major unwanted hemorrhagic effects and mortality rates when compared with the aspirin-clopidogrel combination. ${ }^{32}$ Therefore, independent from the initial therapy, it is based on recommendations that all patients under moderate-high risk of ischemic event including those previously treated with clopidogrel should receive ticagrelor and if the patients could not use ticagrelor, then

\section{Table 10}

The preferences of the physicians in the pharmacological cardioversion of a hemodynamically stable, hypertensive patient with left ventricular hypertrophy for recently started atrial fibrillation are seen.

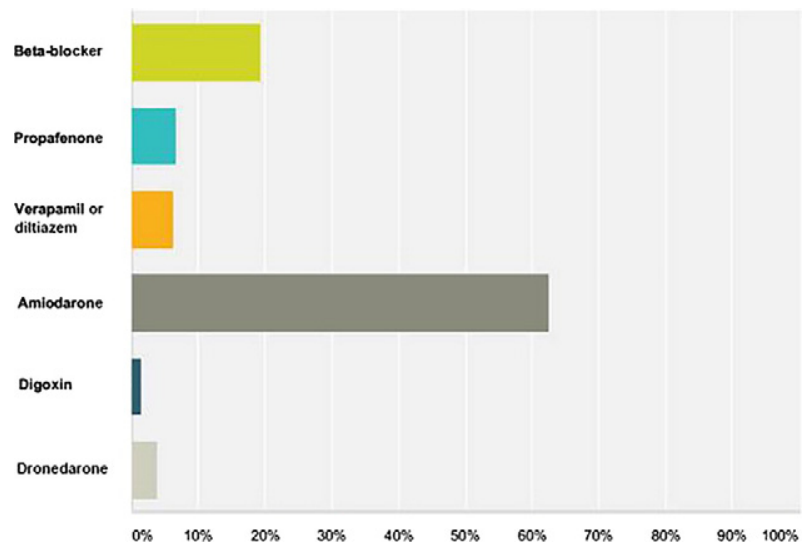

Table 11

Clopidogrel preference rates of the physicians after acute coronary syndrome are seen.

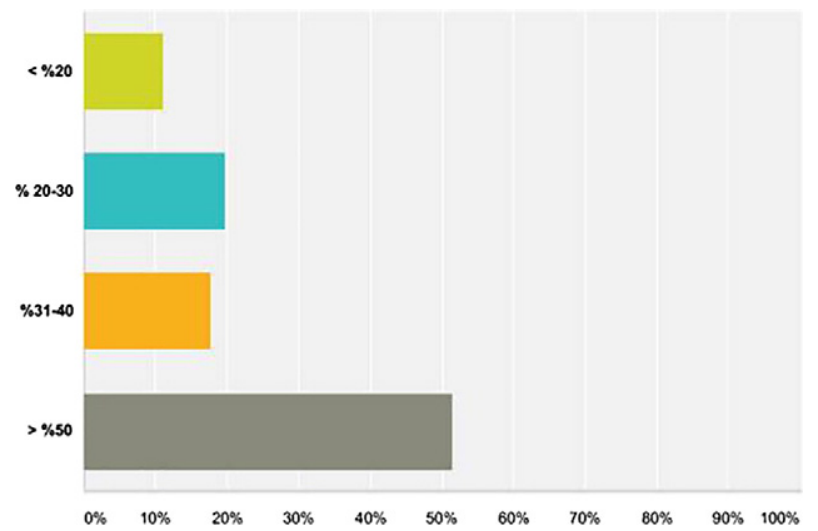

clopidogrel should be used. ${ }^{33}$ However, we detected very high rates of preference for clopidogrel in our study despite the recommendations of the guideline (Table 11).

Aspirin + ticagrelor therapy exerts favorable effects on clinical events within one year after an episode of ACS. However usefulness of maintaining this treatment for longer periods has been a debatable issue. In a study performed on this subject a marked decrease in the risk of cardiovascular death, myocardial infarction and stroke have been detected. ${ }^{34}$ In a questionnaire survey, the physicians were questioned about the preference of ticagrelor for secondary prevention. It has been determined that very scarce number of physicians preferred ticagrelor and most of them inclined to use aspirin (Table 12).

Because of AF, dual antiplatelet use in patients under oral anticoagulant therapy may create problems. In patients who had undergone stenting procedure triple therapy (aspirin + clopidogrel + anticoagulant therapy) should be used. While for patients scheduled for medical or surgical treatment, alternative dual (oral anticoagulant and aspirin or clopidogrel) therapy is recommended. ${ }^{35}$ When physicians were questioned about their preference for the treatment of patients with a CHA2DS2VASc score of 3 who did not undergo stenting procedure after an episode of STEMI, 53\% of them preferred to use anticoagulant + clopidogrel therapy. This preference complied with the recommendations stated in guidelines.

Patients experiencing acute myocardial infarction (MI) should be evaluated before their discharge from the hospital and 6-12 weeks later with echocardiographic tests. Post-MI ejection fraction $<40 \%$ increases the risk of sudden cardiac death. In symptomatic MI patients whose ejection fraction dropped dramatically (NYHA Class 2-3), a waiting period of at least 40 days is recommended for primary prophylaxis for the implantation of intracardiac defibrillator in selected cases. (incomplete revascularization, history of lower EF, development of polymorphic ventricular tachycardia or ventricular fibrillation $48 \mathrm{~h}$ following myocardial infarction) Implantation of ICD may be considered within the first 40 days. Due to lack of randomized controlled studies

\section{Table 12}

The preference rates of the physicians of ticagrelor rather than aspirin for long-term secondary protection are seen.

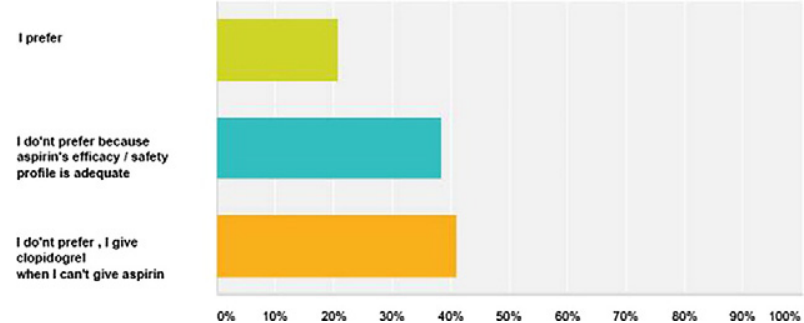




\section{Table 13}

A 42-year-old asymptomatic patient who underwent primary PCI for an anterior myocardial infarction one month ago admitted to our polyclinic for routine control examination. Although the patient was treated according to the guidelines, LVEF was found to be 25$30 \%$. The physicians were asked for ICD treatment in this patient.

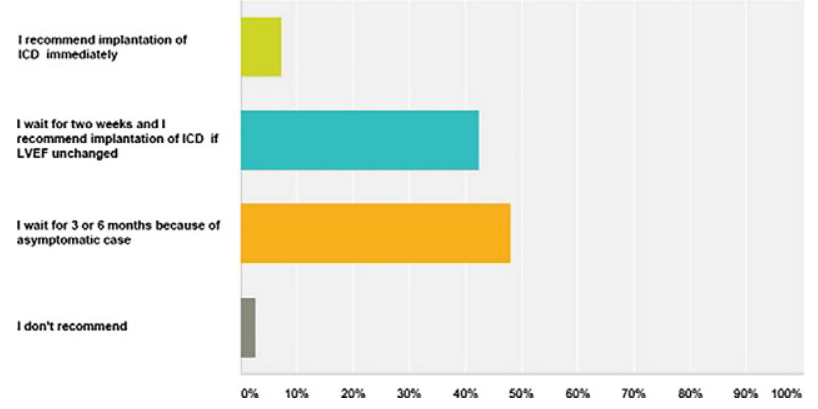

in asymptomatic cases with low EF, implantation of ICD is not recommended. ${ }^{36}$ In our questionnaire when the physicians were asked about their preference of ICD for an asymptomatic patient with an LVEF of 25-30\% who experienced an episode of MI one month previously, most of the physicians preferred to make a decision after a waiting period of 3 or 6 months, $42 \%$ of them recommended ICD implantation after waiting period of 2 weeks in case of persistence of LVEF. Relatively small number of physicians did not recommend implantation of ICD at all (Table 13).

\section{Conclusion}

This questionnaire survey aimed to determine daily practical approaches of the physicians. As a result of the study, apparently clinical applications and preferences of the physicians in the diagnosis and treatment of cardiovascular diseases comply with most of the recommendations in treatment guideline of European Society of Cardiology.

\section{References}

1. Kirchhof P, Benussi S, Kotecha D, et al. 2016 ESC guidelines for the management of atrial fibrillation developed in collaboration with EACTS. Europace 2016;18: 1609-1678.

2. Kirchhof P, Benussi S, Kotecha D, et al. 2016 ESC guidelines for the management of atrial fibrillation developed in collaboration with EACTS. Eur J Cardiothorac Surg 2016;50:e1-e88.

3. Priori SG, Blomstrom-Lundqvist C, Mazzanti A, et al. 2015 ESC guidelines for the management of patients with ventricular arrhythmias and the prevention of sudden cardiac death. Rev Esp Cardiol 2016;69:176 Engl Ed.

4. Roffi M, Patrono C, Collet JP, et al. 2015 ESC guidelines for the management of acute coronary syndromes in patients presenting without persistent ST-segment elevation: Task Force for the Management of Acute Coronary Syndromes in Patients Presenting without Persistent ST-Segment Elevation of the European Society of Cardiology (ESC). Eur Heart J 2016;37:267-315.

5. Authors/Task Force M, Catapano AL Graham I, et al, 2016 ESC/EAS guidelines for the management of dyslipidaemias: the Task Force for the Management of Dyslipidaemias of the European Society of Cardiology (ESC) and European Atherosclerosis Society (EAS) Developed with the special contribution of the European Association for Cardiovascular Prevention \& Rehabilitation (EACPR). Atherosclerosis 2016;253:281-344.

6. Taylor J. 2012 ESC guidelines on acute myocardial infarction (STEMI). Eur Heart J 2012;33:2501-2502.

7. Mitka M. Heart disease a global health threat. JAMA 2004;291:2533.

8. Callow AD. Cardiovascular disease 2005-the global picture. Vascul Pharmacol 2006:45:302-307.

9. Watkins H, Farrall M. Genetic susceptibility to coronary artery disease: from promise to progress. Nat Rev Genet 2006;7:163-173.

10. Petersen S, Peto V, Rayner M, Leal J, Luengo-Fernandez R, Gray A. European Cardiovascular Statistics: 2005 Edition. London: British Heart Foundation; 2005.
11. Abdallah MH, Arnaout S, Karrowni W, Dakik HA. The management of acute myocardial infarction in developing countries. Int J Cardiol 2006;111:189-194.

12. Asia Pacific Cohort Studies C. Joint effects of systolic blood pressure and serum cholesterol on cardiovascular disease in the Asia Pacific region. Circulation 2005;112: 3384-3390.

13. Bastuji-Garin S, Deverly A, Moyse D, et al. The Framingham prediction rule is not valid in a European population of treated hypertensive patients. $J$ Hypertens 2002;20:1973-1980.

14. Conroy RM, Pyorala K, Fitzgerald AP, et al. Estimation of ten-year risk of fatal cardiovascular disease in Europe: the SCORE project. Eur Heart J 2003;24:987-1003.

15. Perk J, De Backer G, Gohlke H, et al. European guidelines on cardiovascular disease prevention in clinical practice (version 2012). The Fifth Joint Task Force of the European Society of Cardiology and Other Societies on Cardiovascular Disease Prevention in Clinical Practice (constituted by representatives of nine societies and by invited experts). Eur Heart J 2012;33:1635-1701.

16. Randomised trial of cholesterol lowering in 4444 patients with coronary heart disease: the Scandinavian Simvastatin Survival Study (4S)Lancet 1994;344:1383-1389.

17. Nicholls SJ, Ballantyne CM, Barter PJ, et al. Effect of two intensive statin regimens on progression of coronary disease. N Engl J Med 2011;365:2078-2087.

18. Langsted A, Freiberg JJ, Nordestgard BG. Fasting and nonfasting lipid levels: influence of normal food intake on lipids, lipoproteins, apolipoproteins, and cardiovascular risk prediction. Circulation 2008;118:2047-2056.

19. Catapano AL, Graham I, De Backer G, et al. 2016 ESC/EAS guidelines for the management of dyslipidaemias. Kardiol Pol 2016;74:1234-1318.

20. Piepoli MF, Hoes AW, Agewall S, et al. 2016 European guidelines on cardiovascular disease prevention in clinical practice. Rev Esp Cardiol 2016;69:939 Engl Ed.

21. Stone NJ, Robinson JG, Lichtenstein AH, et al. 2013 ACC/AHA guideline on the treatment of blood cholesterol to reduce atherosclerotic cardiovascular risk in adults: a report of the American College of Cardiology/American Heart Association Task Force on Practice Guidelines. Circulation 2014;129:S1-45.

22. Avcl A, Demir K, Altunkeser BB. Proprotein convertase subtilisin/kexin type 9 (PCSK9) and inhibitors. Arch Turk Soc Cardiol 2014;42(suppl 2):56.

23. Sabatine MS, Giugliano RP, Wiviott SD, et al. Efficacy and safety of evolocumab in reducing lipids and cardiovascular events. N Engl J Med 2015;372:1500-1509.

24. Ezzati M, Lopez AD, Rodgers A, Vander Hoorn S, Murray CJ, Comparative Risk Assessment Collaborating G. Selected major risk factors and global and regional burden of disease. Lancet 2002;360:1347-1360.

25. Group AS, Group AES, Chew EY, et al. Effects of medical therapies on retinopathy progression in type 2 diabetes. $N$ Engl J Med 2010;363:233-244.

26. Group SR, Wright Jr JT, Williamson JD, et al. A randomized trial of intensive versus standard blood-pressure control. N Engl J Med 2015;373:2103-2116.

27. Wald DS, Law M, Morris JK, Bestwick JP, Wald NJ. Combination therapy versus monotherapy in reducing blood pressure: meta-analysis on 11,000 participants from 42 trials. Am J Med 2009;122:290-300.

28. Gürgün C. Treatment modalities reducing mortality in hypertension. MN Cardiol 2014;21:60-69.

29. Verdecchia P, Reboldi G, Gattobigio R, et al. Atrial fibrillation in hypertension: predictors and outcome. Hypertension 2003;41:218-223.

30. Camm AJ, Lip GY, De Caterina R, et al. 2012 focused update of the ESC guidelines for the management of atrial fibrillation: an update of the 2010 ESC guidelines for the management of atrial fibrillation-developed with the special contribution of the European Heart Rhythm Association. Europace 2012;14:1385-1413.

31. Steg PG, James SK, Gersh BJ. 2012 ESC STEMI guidelines and reperfusion therapy: evidence-based recommendations, ensuring optimal patient management. Heart 2013;99:1156-1157.

32. James S, Akerblom A, Cannon CP, et al. Comparison of ticagrelor, the first reversible oral P2Y(12) receptor antagonist, with clopidogrel in patients with acute coronary syndromes: rationale, design, and baseline characteristics of the PLATelet inhibition and patient Outcomes (PLATO) trial. Am Heart J 2009;157:599-605.

33. Hamm CW, Bassand JP, Agewall S, et al. ESC guidelines for the management of acute coronary syndromes in patients presenting without persistent ST-segment elevation: the Task Force for the management of acute coronary syndromes (ACS) in patients presenting without persistent ST-segment elevation of the European Society of Cardiology (ESC). Eur Heart J 2011;32:2999-3054.

34. Bonaca MP, Braunwald E, Sabatine MS. Long-term use of ticagrelor in patients with prior myocardial infarction. N Engl J Med 2015;373:1274-1275.

35. Roffi M, Patrono C, Collet JP, et al. 2015 ESC guidelines for the management of acute coronary syndromes in patients presenting without persistent ST-segment elevation. Kardiol Pol 2015;73:1207-1294.

36. Priori SG, Blomstrom-Lundqvist C, Mazzanti A, et al. 2015 ESC guidelines for the management of patients with ventricular arrhythmias and the prevention of sudden cardiac death: the Task Force for the Management of Patients with Ventricular Arrhythmias and the Prevention of Sudden Cardiac Death of the European Society of Cardiology (ESC). Endorsed by: Association for European Paediatric and Congenital Cardiology (AEPC). Eur Heart J 2015;36:2793-2867. 